INTERNATIONAL JOURNAL OF

MULTIDISCIPLINARY STUDIES IN ARCHITECTURE

AND CULTURAL HERITAGE

\title{
Redefining Heritage Public Spaces for Cultural Events through the Use of GIS Technology: The Case of El Azhar Street-Cairo
}

\author{
Hala Medhat Aseem a, *, Marwa Adel El-Sayed b \\ a Teaching Assistant, Architecture Engineering Dept., Engineering Faculty, The British University in Egypt \\ b Associate professor, Architecture Engineering Dept., Engineering Faculty, The British University in Egypt
}

\begin{abstract}
"When public spaces are successful [...] they will increase opportunities to participate in communal activity", (Carr, Francis, Rivlin, \& Stone, 1993). The city of Cairo has an enormous number of liveable streets that welcomes cultural events; however, many of such streets lack the design principles that sustain and enhance the occurrence of those events. Trials to investigate and upgrade the urban design of cultural urban spaces have different approaches; one of those new approaches is using Geographic Information System (GIS). The paper aims to evaluate the adequacy of Al-Azhar Street to accommodate cultural events, using GIS, through determining the physical elements of street design that define its functions to foster cultural events and investigating the mutual relationship between cultural events and heritage street design. Al-Azhar Street was selected as one of the main urban spaces in Cairo that witnesses many cultural events throughout the year, while the design of the street doesn "t help in smoothly hosting such events. The research followed an observational field study approach and adopted the GIS as a pilot tool. GIS facilitated creating the needed database for cultural heritage streets, based on a criteria developed by the researchers in relation to international standards reviewed and qualitative data gathered from site observations and inserted. Then, a quantitative analysis of the results of the case study was done using the weighted sum approach. Finally, the research concluded that cultural events are not recommended to take place on $48 \%$ of the area of study and highlighted the urban design dimensions that need to be reconsidered to house cultural events on the street smoothly, which proved the efficiency of using GIS.

\begin{tabular}{ll}
\hline Keywords & \\
- & Redefining Heritage. \\
- & Public Spaces. \\
- & Cultural Events. \\
- & GIS Technology. \\
- & El-Azhar Street.
\end{tabular}
\end{abstract}

\section{Introduction}

"Local culture and identity...shape and give definite meanings to some places and to the urban space as a whole", (Madden, 2012). Therefore, the built environment and culture are tightly related to each other. In a certain way, the design of the built environment carries and promotes culture. The linking element between the environment and culture is the public, (O"Neil, 2006). "When public spaces are successful [...] they will increase opportunities to participate in communal activity",(Carr et al., 1993). Thus, cultural activities and events are a main purpose for gathering people; they are the link between the space and people. 


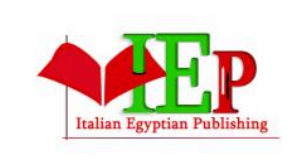

ISSN: $2735-4415$

\section{INTERNATIONAL JOURNAL OF \\ MULTIDISCIPLINARY STUDIES IN ARCHITECTURE \\ AND CULTURAL HERITAGE}

VOLUME 1, ISSUE 1, 2018, $116-128$.

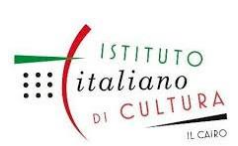

www.egyptfuture.org/ojs/

Cultural heritage is considered a combination of several elements, which are: human processes, activities, and urban elements, (Abdel Tawab, 2014). El Moez, Al-Azhar, \& El-Goharia streets are considered as cultural heritage streets in Egypt. The aim of the paper is to investigate the effect ofcultural events on heritage streets and to determine whether Al Azhar street is a suitable heritageplace for accommodating cultural events or not, using a new technological approach "GIS". With regard to Egypt's Strategy 2030, cultural events are considered a catalyst that can promote tourism in heritage sites.

\section{Importance of livable streets and Heritage Public Spaces:}

Streets are experienced as a three dimensional world, (Wibisono, 2001). According to the (DoEL, 2011), streetscape is "a view or scene of streets, it is the visual elements of a street, including the road, adjoining buildings, sidewalks, street furniture, trees and open spaces, etc, that combine to form the street's character".

Liveable streets are efficient for cities and for creating a better quality life according to Jacobs, 1961. Other researchers, such as: (Ewing et al., 2013) and (Carmona, Tiesdell, Heath, \& OC, 2003)mentioned the importance of liveable streets and creating a place that gathers people together. (Jacobs, 1961) referred to the importance of sidewalks and their uses in which children play and people get introduced to each other. She also mentioned that vehicles should not sprawl over pedestrians. Moreover, (Lynch, 1972) claimed that traffic routes interrupt cutting through the space; however, pedestrian streets interweave with buildings and traffic routes; thus, they are a base that constructs a healthy human-based place.

According to Jacobs, 1993, streetscape is used in many cities as an influential urban factor which improves the space, and creates places and identity. He stressed that the ratio of 1:2 is a comfortable proportion of building height to street width ratio. According to (Ewing, 2013), proportions of a maximum ratio as high as 3:2 and a minimum ratio as low as 1:6 were also suggested by other researchers. The Scottish government (S.G., 2009) expressed the building height to street width ratio according to three classifications: minor streets: 1:5-1:1, typical streets: 1:3-1:1.5, squares:1:6-1:4. The area of study, Al Azhar Street, is considered a typical street; therefore, the researchers set a building height to street width criterion based on these standards.

Ujang, 2010 stated that the degree of attachment to heritage shopping streets is affected by physicalqualities. As mentioned, the physical qualities are: strategic location, good accessibility, variety in accessibility, proximity to transport nodes, good connectivity, permeability, imageability, a clear sense of direction and identifiable nodes and place markers were used to analyse Tan Hiok Nee shopping street. The suitable arrangement

of products, the variability of products and comfort in circulation also affect the comfort level in the street, ((Wan Hashimah, 2010), cited in (Ujang, 2010)). According to ((Tibbalds, 2001), cited in (Ismail, 2015)), a city is easily subjected to losing its heritage. 


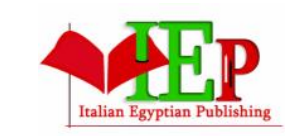

ISSN: $2735-4415$

\section{INTERNATIONAL JOURNAL OF \\ MULTIDISCIPLINARY STUDIES IN ARCHITECTURE \\ AND CULTURAL HERITAGE}

VOLUME 1, ISSUE 1, 2018, $116-128$.

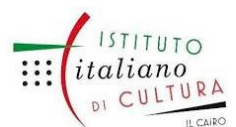

www.egyptfuture.org/ojs/

Yunus, Samadi, \& Omar, 2015 suggested an innovative strategy for heritage streets to make them marketplaces which encourage heritage tourism endeavours. The architecture quality of the heritage streets includes nine elements for their physical attributes (façade design, transport, streetscape, landscape, safety, accessibility, activity, promotion, \& density), and other nine elements for the streets' spiritual attributes (sensory, connectivity, vitality, livability, vibrancy, magnetivity, aura, userfriendly, \& valuability; (Samadi \& Yunus, 2012). The criteria that was set to evaluate the previously mentioned elements were summarized in the following points: façade character, street accessibility, active landscape, street furniture, activity, aerial enclosure, design robustness, \& finally themed ambience; (Samadi, Omar, \& Yunus, 2012). These criteria were graded using a numerical scale from 1 to 9 based on the expertise choice (Yunus, Samadi, Yusop,\& Omar, 2013).

Othman \& Hamzah 2013 established cultural assets to identify people, place, and history relationships. They concluded that there is a strong relationship between both tangible andintangible historical elements and should be developed in parallel to each other. Statistical analysiswas done between Intangible Cultural Heritage in community involvement and ten socio-economicand demographic factors of Malacca city (Bakar, Osman, Bachok, \& Ibrahim, 2014). These factorsare: age, ethnicity, gender, origin, household income, occupation, religion, geographical location,education, and marital status, (Babić, 2015). With reference to (Bakar et al., 2014), cultural resources are divided into two main categories: cultural heritage and natural heritage. The cultural heritage consists of living history sites, historical corridors, residential and commercial historical buildings, while the natural heritage consists of all the surrounding natural landscape. Othman \& Hamzah 2013 divided the cultural resources into five main categories: space and facilities, festivalsand events, creative and art cultural industries, community art and cultural organization, and finally, creative cultural occupations.

In fact, Rodríguez Algeciras, Gómez Consuegra, \& Matzarakis, 2016 and Ismail, 2015 mentionedthat the most important elements that affect the success of promoting cultural events in heritage streets are the street design and landscape, as well as, the heritage style and robustness of the designof the surrounding buildings, followed by the location of the heritage site.

\section{The Use of Technology in Documenting Heritage Sites:}




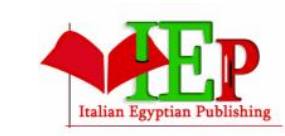

ISSN: $2735-4415$

\section{INTERNATIONAL JOURNAL OF \\ MULTIDISCIPLINARY STUDIES IN ARCHITECTURE \\ AND CULTURAL HERITAGE}

VOLUME 1, ISSUE 1, 2018, $116-128$.

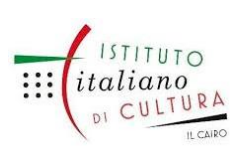

www.egyptfuture.org/ojs/

Yunus et al., 2013 used an expert software choice in Penang and Melaka to make it easier to analyze the heritage street data. The advantage of this software was to help the decision makers reach the ultimate decisions with a clear picture through visual integration. Jang, Choe, \& Kim, 2015 proposed a systematic urban media framework where users can use media contents and shareexperiences which promote heritage sites. Recently, Ismail, 2015 used GIS as a tool to document the heritage streets elements in an organized database.

\subsection{The Use of GIS in Heritage Studies:}

Over the last decade, the evolution of technology has been burgeoning. One of the modern technological tools that is recently used and introduced in the field of Heritage is GIS. GIS contributed to analyzing the aspects of local heritage landscape through mapping thematic analysesfor architectural and construction details of historic buildings and their construction geographies, (Summerby-Murray, 2001). This aided in suggesting recommendations to the policy. Similarly, quality GIS maps were generated to help in surveying the efficiency of the different variables of the urban planning system in a heritage site, such as: transportation system and infrastructure, and check the corresponding impact on heritage tourism, (Al-Kheder \& Khrisat, 2007). Furthermore, Ayhan \& Mert Cubukcu, 2010 explored whether the spatial development of the urban form is related to the distribution of historical mosques over a city space. They used GIS/spatial statistics- based analyses and found out that the chronological establishment of worship buildings may express the phases of city development.

Accordingly, it has been acknowledged that GIS is considered as a novel tool in the heritage research area. However, there is a scarcity of resources concerning the use of GIS in taking decisions concerning the adequacy of heritage sites for cultural events. Therefore, the researchers decided to adopt GIS as one of the pilot tools that can be used in collecting data, analysing and producing results for decision making in the field of urban heritage planning and design.

\section{Methodology}

The research adopted an observational case study methodology. The applied criteria that was subjectively selected is based on both: the data collected from the literature review and site observations. The GIS was used as a tool to support the researchers in analyzing the collected data and reaching easily legible results. The research comprises a collection of substantial amounts of qualitative data that is quantitatively analyzed using the weighted sum approach on GIS. The methodology is divided into three main phases: data collection, data analyses and data established. (see Fig.1)

Data Collection: A site observation was carried out and a set of different previously applied criteria for cultural heritage streets was reviewed, then a new criteria was 


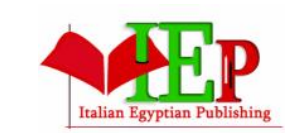

ISSN: $2735-4415$

\section{INTERNATIONAL JOURNAL OF \\ MULTIDISCIPLINARY STUDIES IN ARCHITECTURE \\ AND CULTURAL HERITAGE}

VOLUME 1, ISSUE 1, 2018, 116 - 128.

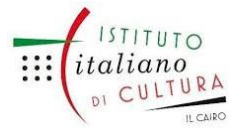

www.egyptfuture.org/ojs/

developed by the researcher to be applied on the case study.

Data Analyses: where the

aforementioned adopted

criteria was imported into

GIS to develop a set of

analyses using weighted

sum approachto reach the

results.

Data Output: the results

reached using the GIS

determined whether the

heritagestreet.

\subsection{GIS Approach:}

The study used ArcMap 10.1 for documenting and analyzing the qualitative data for the area of study. Firstly, the area basemap was drawn using ArcGIS, then the required data was populated in the attribute table. Overlay union command was applied on the data base to reach integrated featureclasses to be ready for the next phase. The following phase was to convert the integrated vector feature classes to raster ones to be able to apply the weighted sum command. Weighted sum approach was utilised as a tool to combine multiple raster data to create an integrated analysis. Each input raster carries its percentage in the overlay process according to its importance in

examining the capability of the street in accommodating cultural events. Referring to what, Rodríguez Algeciras, Gómez Consuegra, \& Matzarakis, 2016 and Ismail, 2015 stated above, the researchers divided the case study criteria into three main dimensions: building scale, street \& plazas, and site location \& accessibility with the following weights, respectively: $20 \%, 60 \%$ and $20 \%$. Each raster data carries a field column to hold one of three values 0 or 1 or 2 , in which 0 means that the specified element is not found and thus the space is not adequate for cultural events, 1 means that the specified element is found but not efficient, and 2 means that the element is foundand efficient.

\subsubsection{Case Study Background:}

Al Azhar Street is one of the main vital heritage streets in Cairo. It is a main stream within streetsof old Cairo. The street is famous for the Islamic medieval architectural 


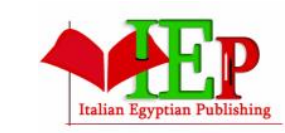

ISSN: $2735-4415$

\section{INTERNATIONAL JOURNAL OF \\ MULTIDISCIPLINARY STUDIES IN ARCHITECTURE \\ AND CULTURAL HERITAGE}

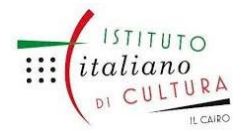

www.egyptfuture.org/ojs/

style, religious and historical buildings that act as a catalyst for hosting celebrations, such as: Al Azhar Mosque, Old Cairo gates, and on the other side, El Hussein Mosque with its plaza. A lot of cultural and religiousfestivals take place on Al Azhar street, such as: Birthday of Prophet Mohamed or El Hussein, andothers.

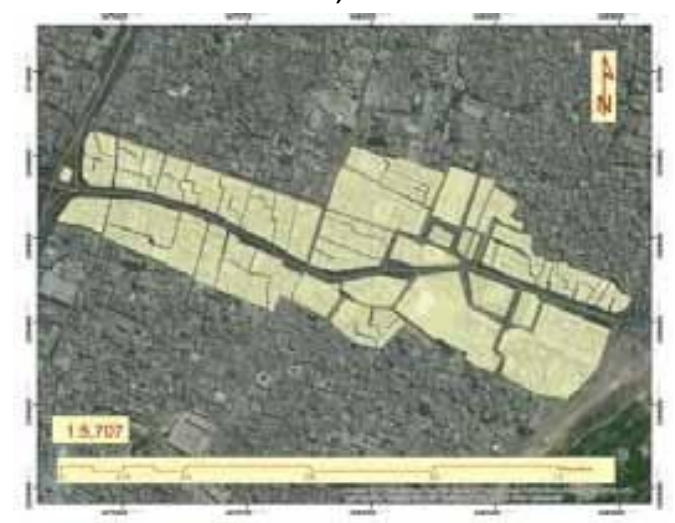

Fig. 2. Map of the site showing Al Azhar street surrounded by the first block of buildings on either sides (Source: authors)

\subsection{Case Study Analysis:}

The practical part of this study started by collecting all the qualitative data for the area of studythrough three consequent phases:

\subsubsection{Data Collection :}

In the previously reviewed literature, previous researchers have generated different sets of requirements for elements that are important for harboring cultural events in heritage streets. A research criteria has been subjectively developed to focus only on the physical attributes that should be fulfilled so that a heritage streets can promote cultural events. The criteria combined three dimensions to assess the suitability of streets to host cultural events. These dimensions are:

1.surrounding building scale (cultural heritage façade \&ground floor activity),

2.streets \& plazas(clear sense of direction, width to height street ratio, streetscape furniture \& landscape, social activities, sidewalks \& street vendors), and 3.site location \& accessibility (strategic location, variety of accessibility, proximity of 


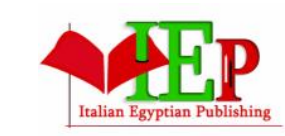

ISSN: $2735-4415$
INTERNATIONAL JOURNAL OF

MULTIDISCIPLINARY STUDIES IN ARCHITECTURE

AND CULTURAL HERITAGE

VOLUME 1, ISSUE 1, 2018, $116-128$.

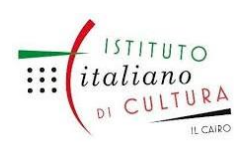

www.egyptfuture.org/ojs/

transport nodes \& parking areas).

\subsubsection{Data Analysis Process:}

The practical part of the study consists of one single geo-database and a number of feature classesthat were imported and populated according to the data collected from the field study. In this phase, the preparation of the database required: first, converting all line and points feature classes into polygon ones to represent the range of services for the selected items, then, adding a field columnthat holds one of the aforementioned attribute scales: 0 or 1 or 2; second, overlaying the feature classes of each data set into one integrated feature class and adding all the attribute raster valuesof each feature class to reach a final accumulated field for all the raster values; after that, the overlaid feature classes were converted to raster ones.

\subsubsection{Data Output}

In this phase, the database was ready for applying the weighted sum command. To be able to applyit, weights were determined, based on the literature review and the point of view of the researchers, for each element of the case study dimensions, as shown in the following table:

Table.1. Distribution of weights for the criteria of analysis (Source: authors) 


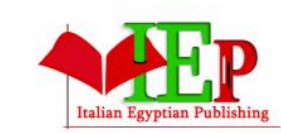

ISSN: $2735-4415$

\section{INTERNATIONAL JOURNAL OF \\ MULTIDISCIPLINARY STUDIES IN ARCHITECTURE \\ AND CULTURAL HERITAGE}

VOLUME 1, ISSUE 1, 2018, $116-128$.

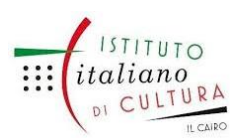

www.egyptfuture.org/ojs/

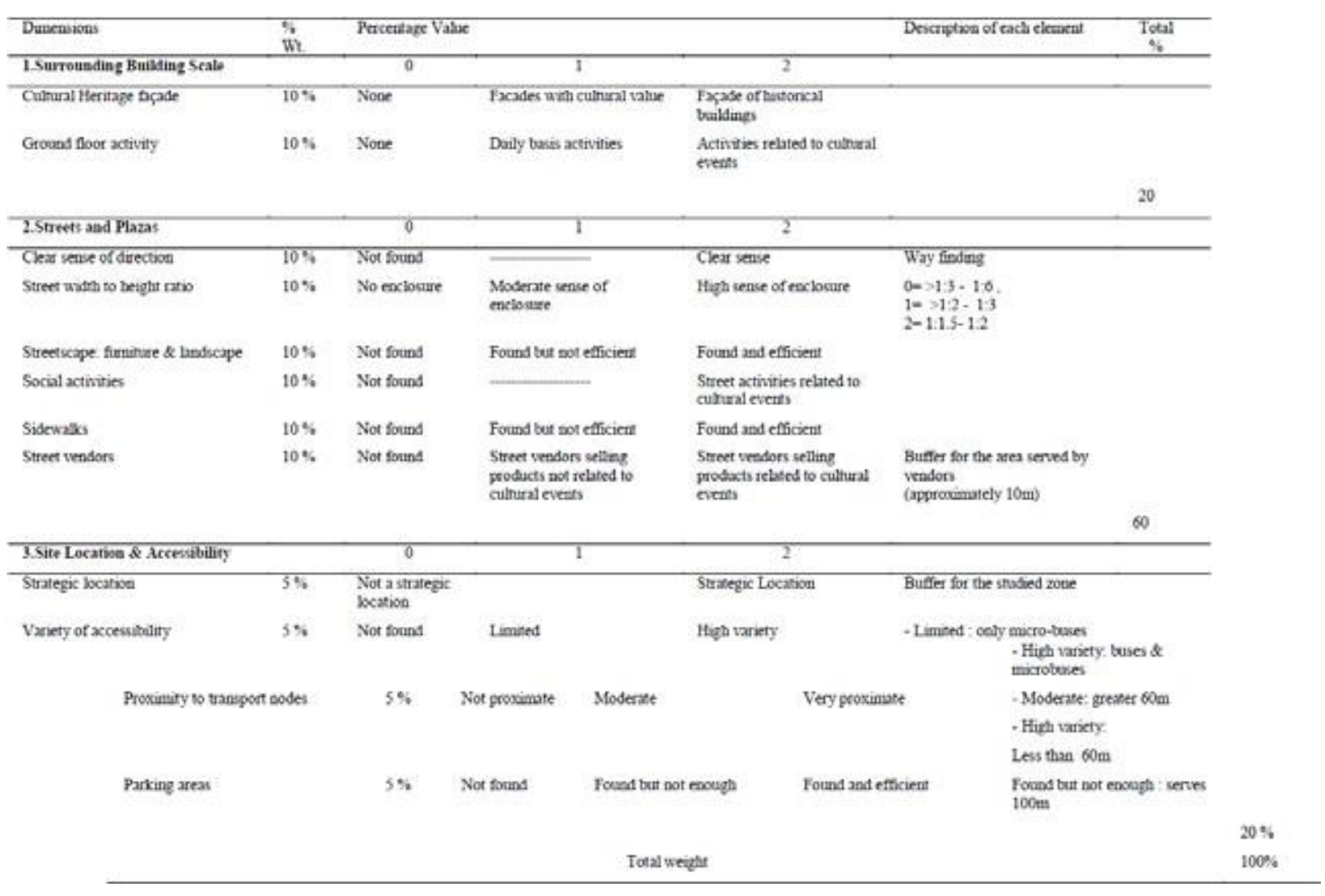

\section{Results and discussion:}

After converting each overlaid feature class into a raster one, several results were concluded from the GIS database. The researchers divided the results into four categories according to the aforementioned three dimensions in addition to an additional "final result" category.

Rodríguez Algeciras, Gómez Consuegra, \& Matzarakis, 2016, Ismail, 2015 and Yunus, Samadi, \& Omar, 2015 stated that cultural heritage facades and ground floor activities are consideered important street elements that encourage hosting the cultural events. After examining these two elements in the current case study, it was realised that, only $20 \%$ of the area of study has historicalfaçade design and the rest are either facades of cultural values or traditional ones. The study area is distinguished with $25.9 \%$ of ground floor activities that could serve cultural events. The previously 


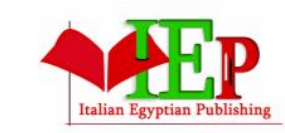

ISSN: $2735-4415$

\section{INTERNATIONAL JOURNAL OF \\ MULTIDISCIPLINARY STUDIES IN ARCHITECTURE AND CULTURAL HERITAGE}

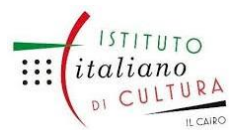

www.egyptfuture.org/ojs/

mentioned two elements were overlaid and converted to raster features to weigh their sum. As shown in the following figure, the overlaid feature of "Surrounding Building Scale" feature classes showed that $63.4 \%$ of the study area is not suitable for hosting cultural events(lightyellow), $16.5 \%$ has a potential (moderate suitability) to accommodate them(red), and finally only $20.1 \%$ is the most suitable for housing cultural events (green). These results support the criteria ofthe previous researchers. (see Fig.3)

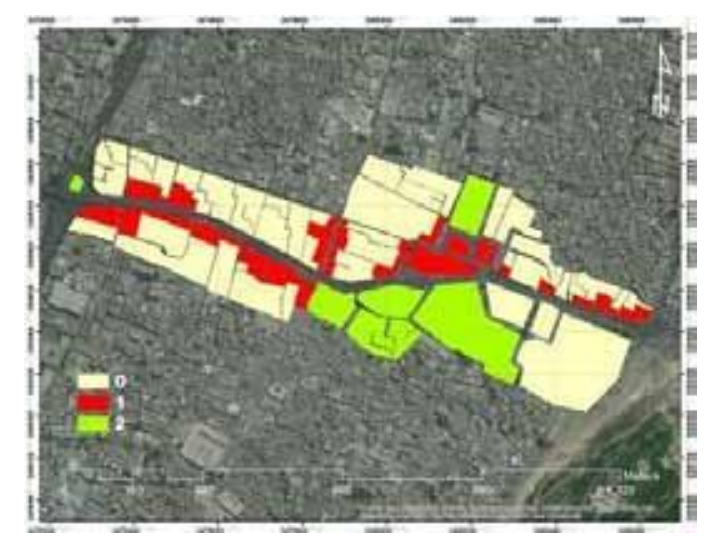

Fig. 3. "Surrounding Building Scale" dimension (Source: authors)

In fact, Rodríguez Algeciras, Gómez Consuegra, \& Matzarakis, 2016, Ismail, 2015 and Bakar et al., 2014 mentioned that clear sense of direction, street width to height ratio, streetscape: furniture \& landscape, social activities, sidewalks and street vendors are considered as important elements that should be found in streets hosting cultural events. By assessing the area of interest accordingto the previously stated elements, it was shown that Al Azhar Street has a clear sense of direction; however, its furniture and landscape aid in accommodating the cultural events with only $25 \%$. A large amount of cultural, social activities took place on Al Azhar Street, inspite of the fact thatonly $17.4 \%$ of the sidewalks are available for use by users. Finally, it was observed that a lot of street vendors took place on the street. These six elements are overlaid as shown in Fig.4 and $17.4 \%$ of the street area is not adequate for cultural events (light yellow), and $52.8 \%$ can moderately accommodate cultural events (red); however, the rest of the area can highly host cultural events (green). The presence of the aforementioned 6 elements on the street is high; thus, a direct proportional result was shown in the weighted overlaid feature which supports the literature study. (see Fig.4) 


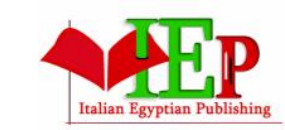

ISSN: 2735-4415

\section{INTERNATIONAL JOURNAL OF \\ MULTIDISCIPLINARY STUDIES IN ARCHITECTURE \\ AND CULTURAL HERITAGE}

VOLUME 1, ISSUE 1, 2018, $116-128$.

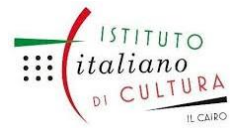

www.egyptfuture.org/ojs/

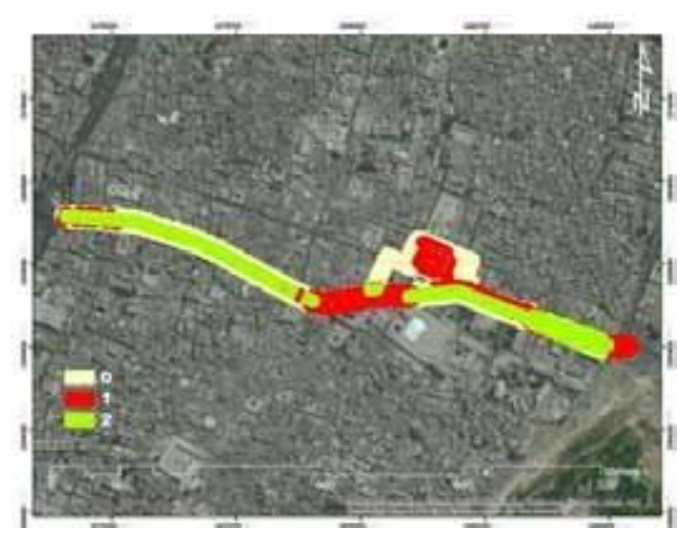

Fig. 4. "Streets and Plazas" dimension (Source: authors)

Strategic location, variety of accessibility, proximity to transport nodes and parking areas were mentioned by Othman \& Hamzah 2013 as essential elements that can support cultural events on heritage streets. Al Azhar street is considered one of the most important central strategic locations all over Cairo with $62.5 \%$ variable transportation facilities, and only $12.5 \%$ of the transport nodes are not proximate to the area of study with one parking lot at the beginning of the street. Finally,it was identified that a probability of 53\% does not support fostering cultural events on the street (light yellow). In spite the fact that $\mathrm{Al}$ Azhar Street has a strategic location, the rest of the elements were not adequate enough to qualify the street to host cultural events.(seeFig.5)

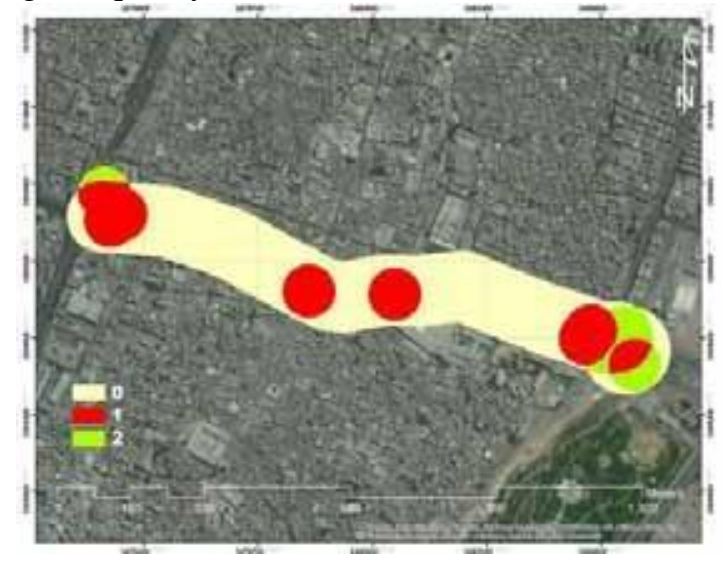

Fig. 5. "Site Location and Accessibility" dimension (Source: authors)

Finally, by using the weighted sum approach with the abovementioned percentages, it has been recognised that cultural events are not recommended to take place on $48 \%$ of the area of study as shown by the light yellow colour in Fig. 6 . The rest of the area 


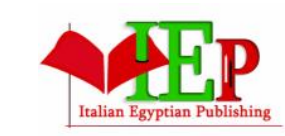

ISSN: $2735-4415$

\section{INTERNATIONAL JOURNAL OF \\ MULTIDISCIPLINARY STUDIES IN ARCHITECTURE \\ AND CULTURAL HERITAGE}

VOLUME 1, ISSUE 1, 2018, $116-128$.

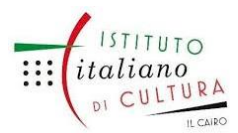

www.egyptfuture.org/ojs/

can either moderately or highly accommodate cultural events with the following percentages respectively: $21 \%$ (red) and 31\%(green). (see Fig.6)

Fig. 6. Final Weighted Sum Overlay Map (Source: authors)

\section{Conclusion}

Looking forward to Egypt"s Strategy 2030, it was perceived that the government policy is lookingforward to encourage tourism. Cultural events are considered as one of the main assets that attractstourists. In this paper, the researchers explored a new pilot method (GIS) to evaluate historical streets in relation to accommodating cultural events. The results of the pilot tool study proved theforeseen outcomes out of the site observation. Not only can this method be used by urban plannersand designers to help them in determining the necessary elements needed for hosting cultural

events in historical heritage streets during the urban planning and design phases, but it can also serve as a tool in setting the weak points that designers should work on in the design of existing streets to encourage holding cultural events in a smooth way.

\section{References}

Abdel Tawab, A. G. (2014). The World Heritage Centre"s approaches to the conservation of New Gourna Village, and the assessment of its authenticity and integrity. Alexandria Engineering Journal, 53(3), 691-704. http://doi.org/10.1016/j.aej.2014.01.010

Al-Kheder, S., \& Khrisat, B. (2007). Assessment of the Urban Planning System in Historic Jerash with GIS: Achievements and Challenges for Sustainable Tourism. Tourism and Hospitality Planning \& Development, 4(3), 245- 266. http://doi.org/10.1080/14790530701797442

Ayhan, I., \& Mert Cubukcu, K. (2010). Explaining historical urban development using the locations of mosques: A GIS/spatial statistics-based approach. Applied Geography, 30(2), 229-238. http://doi.org/10.1016/i.apgeog.2009.05.002

Babić, D. (2015). Social Responsible Heritage Management - Empowering Citizens to Act as Heritage Managers.

Procedia - Social and Behavioral Sciences, 188, 27-34. http://doi.org/10.1016/j.sbspro.2015.03.335

Bakar, A. A., Osman, M. M., Bachok, S., \& Ibrahim, M. (2014). Analysis on Community Involvement Level inIntangible Cultural Heritage: Malacca Cultural Community. Procedia - Social and Behavioral Sciences, 153, 286- 297. http://doi.org/10.1016/i.sbspro.2014.10.062 


\section{INTERNATIONAL JOURNAL OF \\ MULTIDISCIPLINARY STUDIES IN ARCHITECTURE AND CULTURAL HERITAGE}

ISSN: $2735-4415$

VOLUME 1, ISSUE 1, 2018, 116- 128.

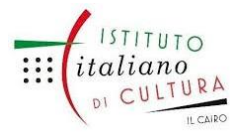

www.egyptfuture.org/ojs/

Boas, V. V. (2015). Artistic Engagement as a Way of Cultural Heritage Preservation in Rio de Janeiro. Procedia

- Social and Behavioral Sciences, 184(August 2014), 180-186. http://doi.org/10.1016/j.sbspro.2015.05.078

Brovelli, M. A., Minghini, M., \& Zamboni, G. (2016). Public participation in GIS via mobile applications. ISPRS Journal of Photogrammetry and Remote Sensing, 114, 306-315. http://doi.org/10.1016/i.isprsjprs.2015.04.002

Carmona, M., Tiesdell, S., Heath, T., \& OC, T. (2003). Public Places, Urban Spaces: The Dimensions of Urban Design (First). Oxford: Architectural Press.

Carr, S., Francis, M., Rivlin, L. G., \& Stone, A. M. (1993). Public Space (Cambridge Series in Environment and Behavior). Cambridge, USA: Cambridge Univrsity Press.

DoEL, D. of the E. L. (2011). American Heritage (Fifth). Houghton Mifflin Harcourt Publishing Company.

Ewing, R. (2013). Eight Qualities of Pedestrian- and Transit-Oriented Design. Retrieved from http://urbanland.uli.org/infrastructure-transit/eight-qualities-of-pedestrian-and-transit-orienteddesign/

Ewing, R., Clemente, O., Neckerman, K. M., Purciel-Hill, M., Quinn, J. W., \& Rundle, A. (2013). Measuring the Urban Design : Metrics for Livable Places (First). Island Press/Center for Resource Economics.

Ismail, W. H. W. (2015). Contemporary Uses of Buildings on a Heritage Street. Procedia - Social and Behavioral Sciences, 170, 633-641. http://doi.org/10.1016/i.sbspro.2015.01.065

Jacobs, A. B. (1993). Great Streets. Berkeley: Massaauchusetts Institute of Technology Press.

Jacobs, J. (1961). The Death and Life of Great American Cities. The Death and Life of Great American Cities, 14. http://doi.org/10.1007/s13398-014-0173-7.2

Jang, S.-Y., Choe, Y., \& Kim, S.-A. (2015). Place Engine: A Dynamic Model of Integrated Humanoriented GIS and Urban Media. Procedia - Social and Behavioral Sciences, 174, 3314-3321. http://doi.org/10.1016/j.sbspro.2015.01.999

Lazzari, M., Danese, M., \& Masini, N. (2009). A new GIS-based integrated approach to analyse the anthropic- geomorphological risk and recover the vernacular architecture. Journal of Cultural Heritage, 10(SUPPL. 1), 104-111. http://doi.org/10.1016/j.culher.2009.10.003

Lynch, K. (1972). What Time this Place. Cambridge, USA: Massachusetts Institute of Technology Press MediaDepartment.

Madden, D. J. (2012). Cities Full of Symbols: A Theory of Urban Space and Culture. (P. J. M. Nas, Ed.). Leiden, NL: Leiden University Press.

O"Neil, D. (2006). What is Culture? Retrieved October 20, 2015, from http://anthro.palomar.edu/culture/culture 1.htm

Othman, R. N. R., \& Hamzah, A. (2013). Interdependency of Cultural Heritage Assets in the Old Quarter, Melaka Heritage City. Procedia - Social and Behavioral Sciences, 105, 577-588.

http://doi.org/10.1016/j.sbspro.2013.11.061 


\section{INTERNATIONAL JOURNAL OF \\ MULTIDISCIPLINARY STUDIES IN ARCHITECTURE}

AND CULTURAL HERITAGE

Rodríguez Algeciras, J. A., Gómez Consuegra, L., \& Matzarakis, A. (2016). Spatial-temporal study on the effects of urban street configurations on human thermal comfort in the world heritage city of Camagüey-Cuba. Building and Environment, 101, 85-101. http://doi.org/10.1016/j.buildenv.2016.02.026

S.G., T. S. G. (2009). The Scottish Government Guidelines. Retrieved from http://www.gov.scot/Publications/2009/01/27140909/6

Samadi, Z., Omar, D., \& Yunus, R. M. (2012). On-Street Visual Analysis on Outdoor Space of Jalan Hang Jebat, Melaka. Procedia - Social and Behavioral Sciences, 68, 353-362. http://doi.org/10.1016/i.sbspro.2012.12.233

Samadi, Z., \& Yunus, R. M. (2012). Conflict of Image and Identity in Heritage Commercialization. Procedia - Social and Behavioral Sciences, 50(July), 675-684. http://doi.org/10.1016/j.sbspro.2012.08.070

Summerby-Murray, R. (2001). Analysing Heritage Landscapes with Historical GIS: Contributions from problem- based inquiry and constructivist pedagogy. Journal of Geography in Higher Education, 25(1), 37-52. http://doi.org/10.1080/03098260020026624

Ujang, N. (2010). Place Attachment and Continuity of Urban Place Identity. Journal of EnvironmentBehaviour Studies, 61-76. http://doi.org/10.1016/j.sbspro.2012.07.014

Wibisono, B. H. (2001). Transformation of Jalan Malioboro, Yogyakarta: The Morphology and Dynamics of aJavanese Street, 1-365.

Yunus, R. M., Samadi, Z., \& Omar, D. (2015). Making of “Great Heritage Street." Procedia - Social and Behavioral Sciences, 168, 1248-1261. http://doi.org/10.1016/j.sbspro.2014.10.242

Yunus, R. M., Samadi, Z., Yusop, N. M., \& Omar, D. (2013). Expert Choice for Ranking Heritage Streets.

Procedia - Social and Behavioral Sciences, 101, 465-475.

http://doi.org/10.1016/i.sbspro.2013.07.220

Received: February 15, 2018

Accepted: April 20, 2018 